\title{
Python software to transform GPS SNR wave phases to volumetric water content
}

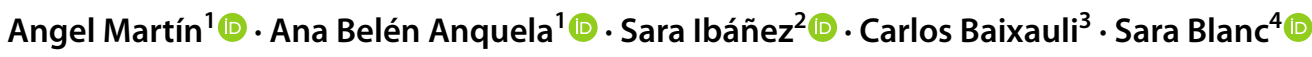

Received: 30 April 2021 / Accepted: 7 October 2021 / Published online: 27 October 2021

(c) The Author(s) 2021

\begin{abstract}
The global navigation satellite system interferometric reflectometry is often used to extract information about the environment surrounding the antenna. One of the most important applications is soil moisture monitoring. This manuscript presents the main ideas and implementation decisions needed to write the Python code to transform the derived phase of the interferometric GPS waves, obtained from signal-to-noise ratio data continuously observed during a period of several weeks (or months), to volumetric water content. The main goal of the manuscript is to share the software with the scientific community to help users in the GPS-IR computation.
\end{abstract}

Keyword GNSS-IR reflectometry $\cdot$ Python software $\cdot$ Soil moisture $\cdot$ Signal-to-noise ratio (SNR)

\section{Introduction}

Using the global navigation satellite system (GNSS) signalto-noise (SNR) observables to monitor soil moisture, also called GNSS interferometric reflectometry (GNSS-IR), is

\footnotetext{
The GPS Tool Box is a column dedicated to highlighting algorithms and source code utilized by GPS engineers and scientists. If you have an interesting program or software package you would like to share with our readers, please pass it along; e-mail it to us at gpstoolbox@ngs.noaa.gov. To comment on any of the source code discussed here, or to download source code, visit our website at http://www.ngs.noaa.gov/gps-toolbox. This column is edited by Stephen Hilla, National Geodetic Survey, NOAA, Silver Spring, Maryland, and Mike Craymer, Geodetic Survey Division, Natural Resources Canada, Ottawa, Ontario, Canada.
}

Angel Martín

aemartin@upvnet.upv.es

1 Department of Cartographic Engineering, Geodesy and Photogrammetry, Universitat Politècnica de València, Camino de Vera s/n, 46022 Valencia, Spain

2 Centro Valenciano de Estudios Sobre el Riego, Universitat Politècnica de Valencia., Camino de Vera S/N, 46022 Valencia, Spain

3 Centro de Experiencias Cajamar, 46200 Paiporta, Valencia, Spain

4 Institute of Information and Communication Technologies, Universitat Politècnica de Valencia, Camino de Vera S/N, 46022 Valencia, Spain a well-known technique. For comprehensive literature on GNSS-IR, refer to Larson et al. (2008a, 2008b), Larson et al. (2010), Larson and Nievinski (2013), Chew et al. (2014, 2015, 2016), Small et al. (2016), Wan et al. (2015), Chen et al. (2016), Roussel et al. (2016), Vey et al. (2016), Zhang et al. (2017), Roesler and Larson (2018), or Martín et al. (2020a).

The primary technique is to use continuous SNR observables for satellites tracks between 5 and 30 elevation angles and convert the SNR observed in $\mathrm{dB}-\mathrm{Hz}$ units to a linear scale in volts. Then, the reflected signal is isolated by fitting a second-order polynomial to the $S N R$ (in volts) to eliminate the direct satellite signal, and finally, the reflected signal is modeled assuming a sinusoidal behavior, using the following expression:

$S N R_{\text {linear }}^{\text {reflected }}=A \cos \left(\frac{4 \pi h}{\lambda} \sin e+\emptyset\right)$

where $A$ and $\phi$ are the amplitude and phase of the wave, $\lambda$ is the GNSS signal wavelength, $e$ is the satellite elevation. $h$ is the reflector height, which is the vertical distance between the GNSS antenna phase center and the horizontal reflecting surface, which is assumed to be the distance between the antenna and the floor due to the low signal penetration on the ground.

However, some precautions are needed to ensure good results: (1) rising or setting satellite tracks should be separated (or tagged for the post-processing), since the 
interferogram pattern can differ for rising and setting tracks of the same satellite; (2) Lomb-Scargle periodogram should be computed from the reflected SNR of each satellite track in order to check that only a clear primary wave is observed, that is, tracks with multiple peaks or low maximum average power should be discarded; (3) finally, a good adjustment (with low residuals) between the SNR indirect signal and the sinusoidal wave is needed to consider a track to be valid for a posteriori transformation to volumetric water content (VWC).

The final step is the transformation of wave phase differences from day to day to VWC differences. To do this, in situ observations are needed as a reference data set. These observations can be obtained from soil data samples (Martin et al. 2020a) from conventional water content reflectometer sensors (Larson et al. 2010; Vey et al. 2016) or can be estimated based on the soil type (Larson and Small 2015). Several weeks (or months) of both types of data are necessary to obtain a good linear relationship between GNSS-IR-derived phase variations and reference VWC variations. Usually, a value of $65.1 \%\left(\mathrm{~m}^{3} / \mathrm{m}^{3}\right)$ is used for this linear relationship, implying that a change of $1^{\circ}$ in phase corresponds to a change of $0.015 \mathrm{~m}^{3} / \mathrm{m}^{3}$ in volumetric water content. However, a better slope can be adjusted using the satellite tracks for which the phase variations present a stronger linear correlation with in situ soil moisture variations. This final step reduces the number of valid satellites that can be used in the final soil moisture monitoring because of the low correlation some satellites present with respect to the reference values. For example, in Zhang et al. (2017), this correlation is set at 0.9 , so only the ascending tracks of GPS satellites $13,21,24$, and 30 and the descending tracks of GPS satellites 05, 09, 10,15 , and 23 were used; in Vey et al. (2016), only GPS satellites 2, 8, 14, 17, 23, and 29 were used for the calculations.

Some GNSS-IR open software packages are provided to the scientific community. For example, in Nievinski and Larson (2014), a MATLAB/Octave software is developed, which can produce carrier phase, pseudorange and SNR simulated GPS observations that agree with a multipath model. In Roesler and Larson (2018), a software tool translates GPS (or GNSS) observations into a format usable for reflection research, estimates the dominant frequencies and reflection height, and generates a map of GNSS-IR reflection zones around the antenna.

In Martín et al. (2020b), a software package is presented to transform GPS SNR observations to indirect SNRadjusted waves, where the amplitude and phase of the waves for the good satellite tracks are the final output (https://geode sy.noaa.gov/gps-toolbox/pyGNSS-IR.htm). The software contains some to guarantee that only good indirect SNRadjusted waves are finally saved. This manuscript describes the final piece of software to complete the process, that is, to transform the adjusted phase of the good indirect SNR
GPS waves (output of the previous software package) to daily VWC mean values. To accomplish this transformation, reference values are needed. GNSS observations and reference values are provided with the software to check the correct software execution. They are those reported in Martin et al. (2020a): continuous GNSS observations for 66 days, from December 3, 2018, to February 6, 2019, in the installations of the Cajamar Centre of Experiences, Paiporta, Valencia, Spain (https://www.fundacioncajamarvalencia.es/ es/comun/actividades/) and daily soil samples taken (except weekends) at $5 \mathrm{~cm}$ depth and weighed before and after being dried (gravimetric method) in a laboratory. Additionally, a reference file with daily raining values (in liters by day) is included for the final plot of the results.

\section{Software development}

This software is a continuation of the software tools GPS file.py and SNR_list_satV2.py (https://geodesy.noaa.gov/ gps-toolbox/pyGNSS-IR.htm) coded in python (python 2.7 and 3 can be used), and the input is the output of the SNR list_satV2.py process.

Assuming that the output results of SRN_list_satV2.py software are stored in individual files for every satellite and observed week, the steps of the PhSNR2VWC.py software tool are as follows:

1. From every week output file containing the amplitude and phase for every satellite track, the software generates an internal file with the rising satellite tracks and another with the falling satellite tracks.

2. For both internal rising and falling files and satellite by satellite, the software transforms the adjusted phase to a value between 0 and 180 degrees using the sign of the adjusted amplitude so that all phases are located in a positive wave with positive correlation with respect to reference values. The phase is transformed to VWC using the linear relationship of $65.1 \%\left(\mathrm{~m}^{3} / \mathrm{m}^{3}\right)$, and the user can modify this default value.

3. Mean GPS-derived VWC values per rising or falling track and satellite and day are computed. (This step is included in case a track was interrupted in the observation and two different parts of the same track were computed separately).

4. Outlier detection and elimination: GPS-derived VWC for a day greater or lower than $0.03 \mathrm{~m}^{3} / \mathrm{m}^{3}$ (default value) in comparison with the previous or later one or two days is deleted. The user can modify this threshold because this value cannot be realistic in the case of strong rain conditions.

5. Since the results should be interpreted in a relative way, that is, water content variations from one day to another, 


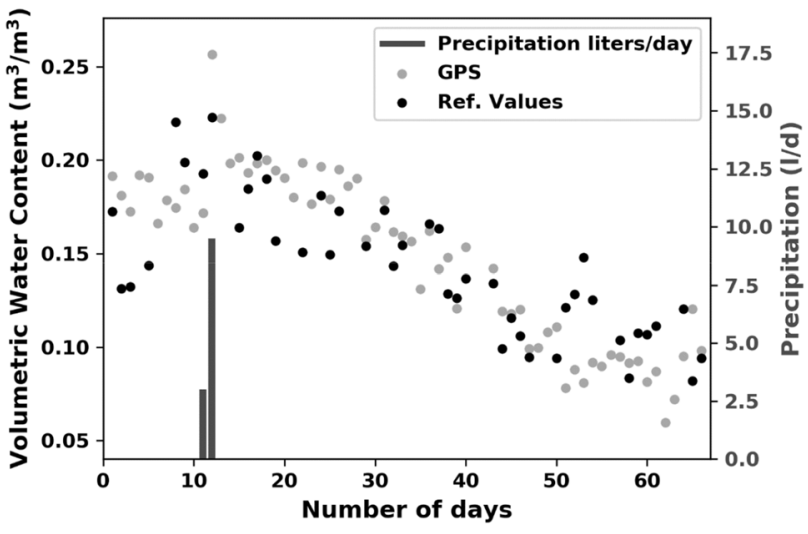

Fig. 1 GPS-derived VWC and reference values for the experiment included with the software

the GPS-derived VWC is reduced to reference data. This is done by computing and applying the offset between the mean GPS-derived VWC values and mean reference values. After this, if a GPS-derived VWC value is below $0.05 \mathrm{~m}^{3} / \mathrm{m}^{3}$ (Vey et al. 2016) or higher than $0.05 \mathrm{~m}^{3} / \mathrm{m}^{3}$ plus the maximum reference value, it is eliminated.

6. Only satellites with more than $20 \%$ of GPS-derived VWC daily values, in comparison with the total observed days, are finally stored (this percentage is per falling or rising track since they are separated in the computation).

7. Only satellites with correlations higher than 0.6 with respect to the reference values are taken for the next step. This correlation value can be modified by the user.

8. Mean GPS-derived VWC daily values are computed using all satellites stored in the previous step. In this step, all falling and rising values are used together.

\section{Software example}

The data we provided with the software are part of an experiment performed in the installations of the Cajamar Center of Experiences, Paiporta, Valencia, Spain, by Martín et al. (2020a). The experiment was performed from December 3, 2018 to February 6, 2019. We provide the output files of SNR_list_satV2.py for every one of the ten observed weeks. Additionally, a reference file with the daily soil samples reduced by the gravimetric method and a file with the rain values are provided.

The output of PhSNR2VWC.py is shown in Fig. 1, where the daily-GPS-derived VWC values, reference values and rain values are plotted, VWC values are also saved in an output file. In the prompt of the Python console, information about the correlation for every satellite (separated by rising or falling tracks) with respect to the

reference values is shown and, also, information about whether a satellite (separated by rising or falling tracks) has not been considered because lower than $20 \%$ of the total days are good values. Finally, a statistical summary containing the Pearson correlation, root mean square error (RMSE) and mean absolute error (MAE) between GPSderived VWC and reference values is also provided in the prompt. Table 1 presents those statistical values for the example included with the software.

\section{Conclusions and final remarks}

This manuscript presents the main ideas and implementation decisions needed to write the Python code to transform the derived phase of the interferometric GPS waves, obtained from signal-to-noise ratio (SNR) data continuously observed during a period of several weeks (or months), to volumetric water content (VWC). The main intention is to share the software with the scientific community to help users in GNSS-IR computation.

Based on our results, it is important to highlight that, according to the results of SNR_list_satV2.py software, approximately $50 \%$ of all the satellite tracks can be considered good tracks for interferometric reflectometry. Based on the results of the PhSNR2VWC.py software, considering all satellite tracks and all the observation periods (66 days in this example), only $17 \%$ can be considered good satellite tracks for all the days of the experiment and therefore can be used to monitor VWC with good accuracy. Thirty percent are under the $20 \%$ of all observed days, $33 \%$ present a correlation below 0.6 , and the other $20 \%$ are considered as satellite tracks with insufficient satellite information (no good tracks obtained from the output of the SNR_list_SatV2.py software). This means that only a small part of all GPS observations can be used, so the next step is to introduce other satellite constellations in the solution (GLONASS, Beidou and/or Galileo).

Table 1 Statistical summary for the experiment included with the software

\begin{tabular}{ll}
\hline $\begin{array}{l}\text { Pearson correla- } \\
\text { tion }\end{array}$ & 0.8 \\
\hline RMSE & $0.027 \mathrm{~m}^{3} / \mathrm{m}^{3}$ \\
MAE & $0.022 \mathrm{~m}^{3} / \mathrm{m}^{3}$
\end{tabular}


Acknowledgements The authors want to thank the Cajamar Center of Experiences staff for their support and collaboration in the Paiporta experiment. The authors also want to thank anonymous referees for their valuable comments and suggestions.

Funding Open Access funding provided thanks to the CRUE-CSIC agreement with Springer Nature.

Data Availability The software is available from the GPS Toolbox website at https://geodesy.noaa.gov/gps-toolbox/

Open Access This article is licensed under a Creative Commons Attribution 4.0 International License, which permits use, sharing, adaptation, distribution and reproduction in any medium or format, as long as you give appropriate credit to the original author(s) and the source, provide a link to the Creative Commons licence, and indicate if changes were made. The images or other third party material in this article are included in the article's Creative Commons licence, unless indicated otherwise in a credit line to the material. If material is not included in the article's Creative Commons licence and your intended use is not permitted by statutory regulation or exceeds the permitted use, you will need to obtain permission directly from the copyright holder. To view a copy of this licence, visit http://creativecommons.org/licenses/by/4.0/.

\section{References}

Chen Q, Won D, Akos DM, Small EE (2016) Vegetation using GPS interferometric reflectometry: experimental results with a horizontal polarized antenna. IEEE J Sel Top Appl Earth Obs Remote Sens 9(10):4771-4780

Chew CC, Small EE, Larson KM, Zavorotny VU (2014) Effects of near-surface soil moisture on GPS SNR data: development and retrieval algorithm for soil moisture. IEEE T Geosci Remote Sens 52(1):537-543

Chew CC, Small EE, Larson KM, Zavorotny UZ (2015) Vegetation sensing using GPS-interferometric reflectometry: theoretical effects of canopy parameters on signal-to-noise ratio data. IEEE Trans Geosci Remote Sens 53(5):2755-2764

Chew CC, Small EE, Larson KM (2016) An algorithm for soil moisture estimation using GPS-interferometric reflectometry for bare and vegetated soil. GPS Solut 20(3):525-537

Larson KM, Nievinski FG (2013) GPS snow sensing: results from the earthscope plate boundary observatory. GPS Solut 17(1):41-52

Larson KM, Small EE (2015) PBO H2O data portal: documentation and derived data products. https://www.unavco.org/data/gps-gnss/ derived-products/pbo-h2o/documentation/documentation.html\# soil. Accessed Dec 2019

Larson KM, Small EE, Gutmann ED, Bilich AL, Axelrad A, Braun JJ (2008a) Using GPS multipath to measure soil moisture fluctuations: initial results. GPS Solut 12(3):173-177

Larson KM, Small EE, Gutmann ED, Bilich AL, Braun JJ, Zavorotny VU (2008b) Use of GPS receivers as a soil moisture network for water cycle studies. Geophys Res Lett 35:L24405. https://doi.org/ 10.1029/2008GL036013

Larson KM, Braun JJ, Small EE, Zavorotny VU (2010) GPS multipath and its relation to near-surface soil moisture content. IEEE J Sel Top Appl Earth Obs Remote Sens 3(1):91-99
Martín A, Ibañez S, Baixauli C, Blanc S, Anquela AB (2020a) Multiconstellation interferometric reflectometry with mass-market sensors as a solution for soil moisture monitoring. Hydrol Earth Syst Sci. https://doi.org/10.5194/hess-24-3573-2020

Martín A, Luján R, Anquela AB (2020b) Python software tools for GNSS interferometric reflectometry (GNSS-IR). GPS Solut 24:94. https://doi.org/10.1007/s10291-020-01010-0

Nievinski GG, Larson KM (2014) An open source GPS multipath simulator in Matlab/Octave. GPS Solut 18:473-481. https://doi. org/10.1007/s10291-014-0370-z

Roesler C, Larson KM (2018) Software tools for GNSS interferometric reflectometry (GNSS-IR). GPS Solut. https://doi.org/10.1007/ s10291-018-0744-8

Roussel N, Frappart F, Ramillien G, Darroes J, Baup F, Lestarquit L, Ha MC (2016) Detection of soil moisture variations using GPS and GLONASS SNR data for elevation angles ranging from 2 to $70^{\circ}$. IEEE J Sel Top Appl Earth Obs Remote Sens 9(10):4781-4794

Small EE, Larson KM, Chew CC, Dong J, Ochsner TE (2016) Validation of GPS-IR soil moisture retrievals: comparison of different algorithms to remove vegetation effects. IEEE J Sel Top Appl Earth Obs Remote Sens 9(10):4759-4770

Vey S, Güntner A, Wickert J, Blume T, Ramatschi M (2016) Longterm soil moisture dynamics derived from GNSS interferometric reflectometry: a case study for Sutherland, South Africa. GPS Solut 20:641-654. https://doi.org/10.1007/s10291-015-0474-0

Wan W, Larson KM, Small EE, Chew CC, Braun JJ (2015) Using geodetic GPS receivers to measure vegetation water content. GPS Solut 19:237-248

Zhang S, Roussel N, Boniface K, Ha MC, Frappart F, Darrozes J, Baup F, Calvet JC (2017) Use of reflected GNSS SNR data to retrieve either soil moisture or vegetation height from a wheat crop. Hydrol Earth Syst Sci 21:4767-4784

Publisher's Note Springer Nature remains neutral with regard to jurisdictional claims in published maps and institutional affiliations.

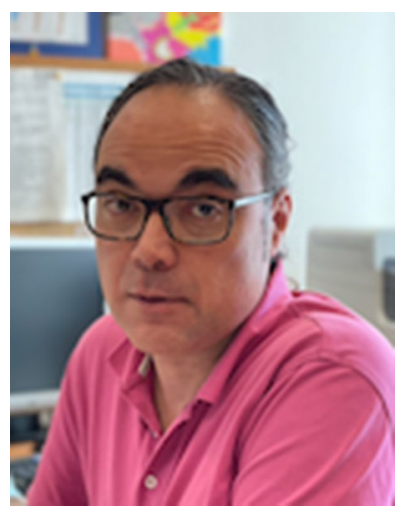

Angel Martín received his Ph.D. degree in Geodesy and Cartography at Universitat Politècnica de València (UPV) in 2001. He is a senior scientist and a lecturer professor at the Department of Cartographic Engineering, Geodesy and Photogrammetry at UPV. His main research areas are GNSS, Physical Geodesy, and Big Data, and Machine Learning applied to Geosciences. 


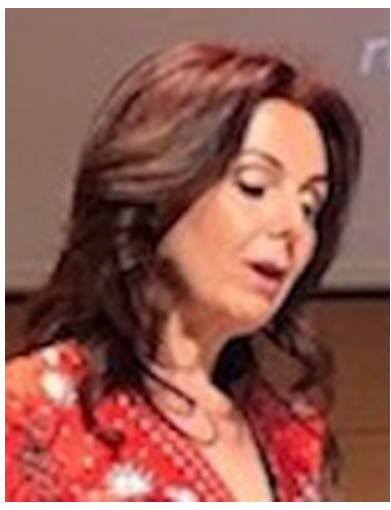

Ana Belén Anquela received her Ph.D. degree in Geodesy and Cartography at Universitat Politècnica de València (UPV) in 2001 and is a senior scientist and a lecturer professor at the Department of Cartographic Engineering, Geodesy and Photogrammetry at UPV. Her main research areas are GNSS and geodetic monitoring. She is the director of the geomatic school at UPV.

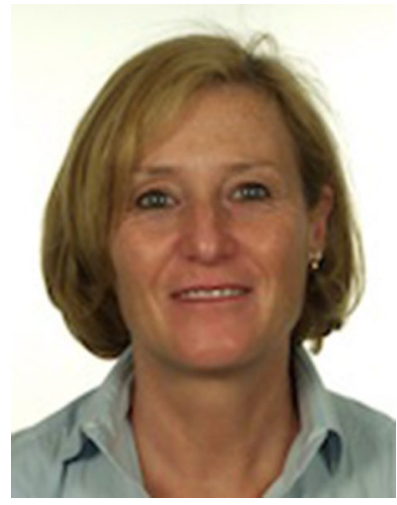

Sara Ibáñez received his Ph.D. degree in Agricultural Engineering at Universitat Politècnica de València (UPV) in 2001. He is a senior scientist and a lecturer professor at the Department of Plant Production at UPV. Her research areas are analysis and quantification of soil degradation, soil quality, operation and storage of carbon in wetlands, and monitoring the impact of climate change on soil salinization and its capacity to retain carbon.

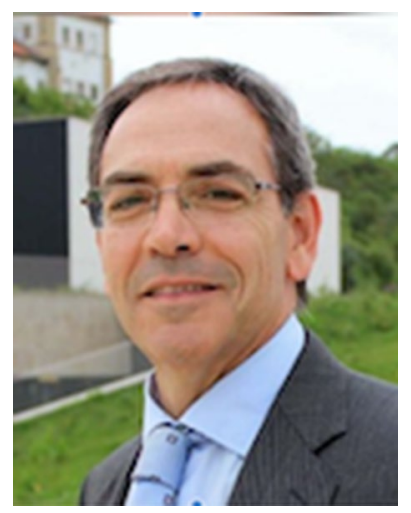

Carlos Baixauli is the Director Experimental Field of Cajamar in Paiporta (Valencia) and holds a Ph.D. in Agronomy from the University Politécnica of Valencia UPV. He has developed his scientific career in Fundación Cajamar since 1992 and as an associated professor of UPV from 2009 to 2014 . He is the President of Spanish Horticultural Science (SECH).

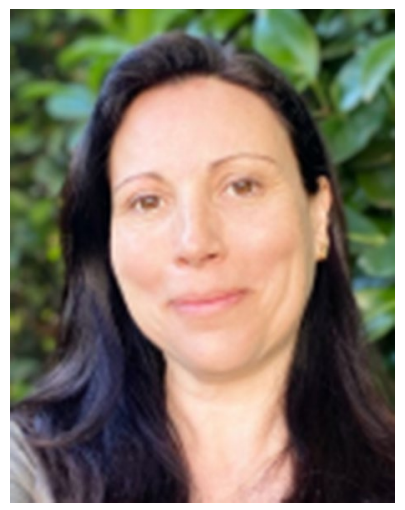

Sara Blanc received a $\mathrm{Ph} . \mathrm{D}$. degree in Informatics at Universitat Politècnica de València (UPV) in 2004. She is a senior scientist and a lecturer professor at the Department of Computer Engineering at UPV, researching IoT, embedded systems, and communication. 